\title{
Urban soil environmental quality in the Yangtze River Economic Zone, China
}

\author{
SHIQI TANG ${ }^{1,2^{*}}$, HANGXIN CHENG ${ }^{1,2}$, KE YANG $^{1,2}$ \\ ${ }^{1}$ Institute of Geophysical\&Geochemical Exploration, Chinese \\ Academy of Geological Sciences,Langfang \\ 065000,China(642191779@qq.com) \\ ${ }^{2}$ Research Center of Geochemical Survey and Assessment on \\ Land Quality,China Geological Survey,Langfang \\ 065000,China
}

The Yangtze River Economic Zone is one of the key regions to China's economy and a densely populated area. The National Multi-Purpose Regional Geochemical Survey (NMPRGS) has been carried out in China since 1999. Generally, top soils at $0-20 \mathrm{~cm}$ depth were collected symmetrically at a density of 1 sample $/ \mathrm{km}^{2}$, while deep soils at $150-180 \mathrm{~cm}$ depth were collected at a density of 1 sample $/ 4 \mathrm{~km}^{2}$. Using the existing top and deep soil data, the Igeo values were calculated for each city individually and all together, where city scope was based on the urban planning area.

Overall, the different elements can be ranked in descending order by $I_{\text {geo }}$ as follows: $\mathrm{Hg}(0.82)>\mathrm{Cd}(0.35)>$ $\mathrm{Pb}(-0.20)>\mathrm{Zn}(-0.27)>\mathrm{Cu}(-0.32)>\mathrm{As}(-0.57)>\mathrm{Cr}$ $(-0.63)>\mathrm{Ni}(-0.68)$. The results imply that, on a regional scale, urban soils in Yangtze River Economic Zone are uncontaminated to moderately contaminated by $\mathrm{Hg}$ and $\mathrm{Cd}$.

$I_{\text {geo }}$ of $\mathrm{Hg}$ of each city shows that 4 cities are at the level of moderately to heavily contaminated, namely Shaoxing (2.82), Ningbo (2.39), Suzhou (2.12) and Wuxi (2.28), and 23 cities appear moderately contaminated. Hg contamination is concentrated in economically developed provinces such as Zhejiang and Jiangsu, and the high-value areas of top soil $\mathrm{Hg}$ are mainly concentrated in the old or central urban areas. Long-term industrial development and human activities could be the main causes of urban mercury contamination.

The results of $\mathrm{Cd}$ of each city show that Zhuzhou is the city with the most serious $\mathrm{Cd}$ contamination and reach the heavily contaminated level(3.42). Chenzhou (2.91), Huangshi (2.56), Xiangtan (2.41), and Hengyang (2.31) are at the moderately to heavily contaminated level. In addition, 18 cities appear moderately contaminated. Further analysis shows that urban soil cadmium contamination is mainly related to mining activities and geological background. 